\title{
No evidence of linkage between the transforming growth factor-alpha gene in families with apparently autosomal dominant inheritance of cleft lip and palate
}

\author{
G M Vintiner, S E Holder, R M Winter, S Malcolm
}

\begin{abstract}
Eight families have been identified with cleft lip, with or without cleft palate (CL/ $P)$, inherited in an apparently autosomal dominant manner. Transforming growth factor-alpha (TGFA) has been tested as a candidate gene for clefting in these families. Negative lod scores were generated in an autosomal dominant model with $80 \%$ penetrance $(Z=-3.152$ at $\theta=0.05$ and $Z=-2.49$ at $\theta=0.05$ with only affected subjects scored). After testing with a reduced penetrance of $28 \%$, less negative lod scores were generated $(Z=-0 \cdot 157$ at $\theta=0.00$ ), but there was still no evidence of linkage. An autosomal recessive model with a penetrance of $35 \%$ was also tested. Regardless of the model used there was little evidence of linkage between TGFA and the CL/P phenotype, which is in contrast to the previously published findings of an association between TGFA and CL/P in unrelated subjects.
\end{abstract}

The incidence of $C L / P$ in the general population is between 1 in 700 and 1 in 1000 live births. However, after the birth of a child with isolated $\mathrm{CL} / \mathbf{P}$, the empirical recurrence risk is about 1 in 25 , although the risk varies depending on the severity of the cleft. The appreciable increase in risk suggests that genetic factors contribute to the development of this malformation. ${ }^{1}$

In 1986, Chung et al reanalysed published Danish pedigree data and proposed a gene of major effect for CL/P. In this study, the model of best fit was the action of a major gene, with autosomal recessive inheritance modified by additional genetic or environmental factors or both. In an attempt to identify this major gene, Ardinger $e t a l^{3}$ carried out an association study using various growth factors and growth factor receptors as candidate genes. A significant association was found between $\mathrm{CL} / \mathrm{P}$ and restriction fragment length polymorphisms at the TGFA locus. The confirmation of this association in two other studies ${ }^{45}$ suggests that an abnormality within or near the TGFA gene may underlie a predisposition to clefting in some subjects.

Hecht $e t a l^{6}$ have carried out a segregation analysis with clefted families from a US Caucasian population and have suggested an autosomal dominant mode of inheritance with reduced penetrance as the model most appro- priate for these families. Indeed, some families exist where isolated $\mathrm{CL} / \mathrm{P}$ appears to be inherited as an autosomal dominant trait albeit with some non-penetrance and incomplete expression. It would appear in these families that the transmission of a major gene from parent to child is causing the occurrence of $C L / P$.

We have used the polymorphisms detected by TGFA for linkage analysis in eight families with apparently dominant inheritance of CL/ $P$. The data were analysed with three models. Two models tested for autosomal dominant inheritance and in one of these the reduced penetrance as suggested by Hecht et $a l^{6}$ was used. The third model, proposed by Chung et $a l^{2}$ was an autosomal recessive model with reduced penetrance. One affected subject from each family was included in an association study. ${ }^{4}$

\section{Materials and methods}

CLINICAL DETAILS AND PEDIGREE INFORMATION Clinical details of two families (families 5 and 7) have been reported previously. ${ }^{7} \mathrm{~A}$ further six families were included in this analysis. Pedigrees of all eight families are presented in the figure. A person was considered to be affected if there was either a bilateral or unilateral cleft of the upper lip with or without a cleft palate. One subject (II.3 in family 1) was judged affected with a 'forme fruste' of cleft lip (a thick white line on the philtrum and a notch of the upper lip). Affected subjects were examined for additional dysmorphic features to exclude the occurrence of syndromes where CL/P was a feature. Particular emphasis was placed on examination of the lips in both affected and unaffected subjects to exclude Van der Woude syndrome.

Blood samples were obtained from 60 subjects. DNA was extracted by standard methods. Chromosome studies were carried out on an affected subject from each of the families. All karyotypes were normal.

\section{DNA PROBES USED}

Three different polymorphisms at the TGFA locus were used to construct a haplotype. TGFA has been mapped to chromosome 2p13. Two genomic subclones were used. phTGF1$10-925$ is a $0.93 \mathrm{~kb}$ insert contained in the vector pBR327. phTGF1-10-3350 is a $3.5 \mathrm{~kb}$ insert in pBR327. Both inserts are excised with 
Family 1

1

II

III

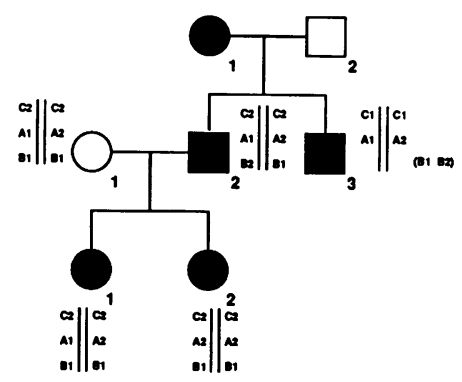

Family 3

1

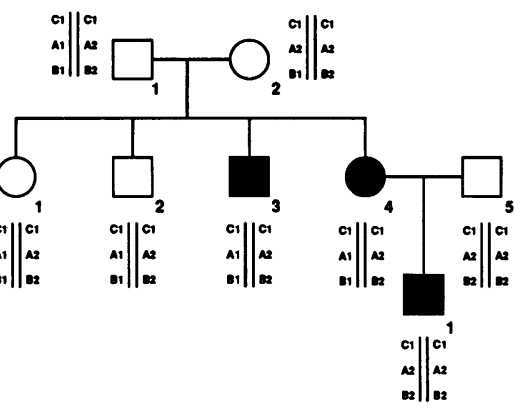

Family 2

I

II

III

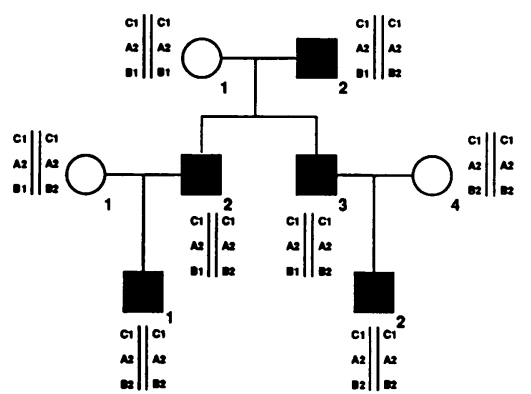

Family 4

II

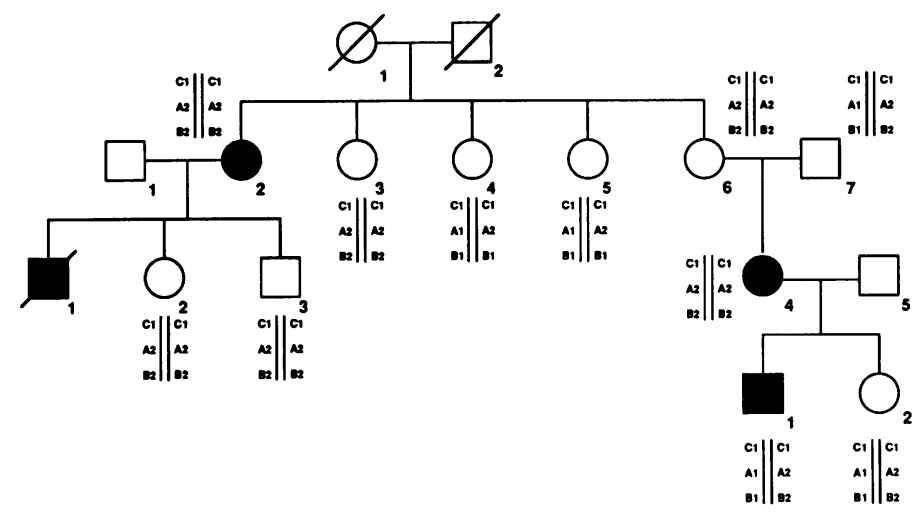

Family 5

Family 6

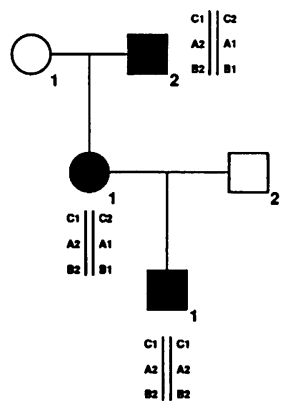

I

II

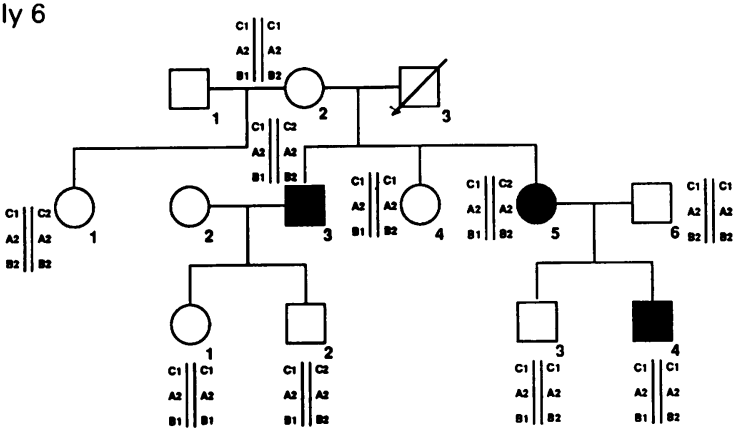

Family 7

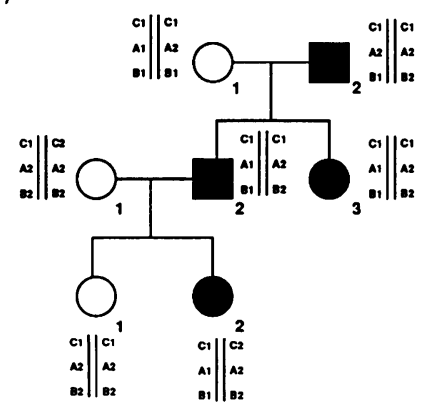

Family 8

1

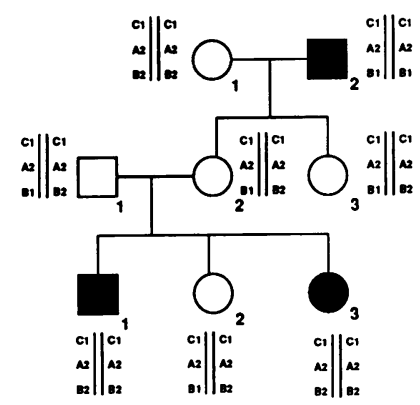

Pedigrees of families with $C L / P$. The haplotypes are drawn alongside. $C 1, C 2=3.0 \mathrm{~kb}$ and $2.7 \mathrm{~kb}$ fragments, TaqI digest. $A 1, A 2=9.0 \mathrm{~kb}$ and $3.7 \mathrm{~kb}$ fragments, BamHI digest. $B 1, B 2=1.5 \mathrm{~kb}$ and $1.2 \mathrm{~kb}$ fragments, RsaI digest.

$E c o$ RI.$^{89}$ Details of the polymorphic fragments associated with these probes are given in table 1.

DETECTION OF POLYMORPHISMS

Restriction endonuclease digestion was carried out under recommended conditions (Northumbria Biologicals Ltd). The DNA was separated by electrophoresis in $0.8 \%$ agarose, denatured in $1.49 \mathrm{~mol} / 1 \mathrm{NaCl} / 0.5 \mathrm{~mol} / 1 \mathrm{NaOH}$ solution then transferred directly to nylon transfer membranes (Hybond-N+, Amersham) in $20 \times$ SSC.

Inserts were excised from the vectors and oligolabelled with ${ }^{32} \mathrm{P}$, then preannealed with boiled sonicated human DNA at a concentration of $10 \mathrm{mg} / \mathrm{ml}$ for 30 minutes at $65^{\circ}$ to compete out repetitive sequences. Probes were 
Table 1 Polymorphisms at the TGFA locus.

\begin{tabular}{lcccc}
\hline Probe & Restriction enzyme & Fragment $(\mathrm{kb})$ & Allele $^{*}$ & Frequency \\
\hline phTGF1-10-3350 & TaqI & 3.0 & C1 & 0.94 \\
& & $2 \cdot 7$ & C2 & 0.06 \\
& BamHI & $9 \cdot 0$ & A1 & 0.19 \\
phTGF1-10-925 & \multirow{2}{*}{ RsaI } & 3.7 & A2 & 0.81 \\
& & 1.5 & B1 & 0.29 \\
& & 1.2 & B2 & 0.71 \\
\hline
\end{tabular}

*Designations are as found in Human Gene Mapping 9 (1987).

hybridised to filters overnight at $65^{\circ} \mathrm{C}$, then washed in $0.1 \times \mathrm{SSC}, 0.1 \% \mathrm{SDS}$ at $65^{\circ} \mathrm{C}$. Filters were exposed to $x$ ray film at $-70^{\circ} \mathrm{C}$ for seven days.

GENETIC LINKAGE ANALYSIS

Haplotypes of the three polymorphisms were constructed for all subjects at the TGFA locus and are included with the pedigree information in the figure. The lod score for genetic linkage was calculated using the LIPED program and a haplotype frequency of 0.25 was assigned. This did not bias the lod score as all four marker haplotypes for the earliest generation of each pedigree, and for persons marrying into the pedigree, could always be inferred. For analysis of our families by the autosomal dominant model, penetrance was first set at $80 \%$ with a gene frequency of 0.001 . The second model was also an autosomal dominant model with the same gene frequency; however, the penetrance was reduced to $28 \%$. This value was obtained by averaging the separate penetrances which were set for males and females in the original analysis. ${ }^{10}$ The final model tested autosomal recessive inheritance with a gene frequency of 0.035 and an average penetrance of $35 \% .^{2}$

\section{Results}

Six of the pedigrees were three generation families (families $1,2,4,5,7,8$ ) with non- penetrance in families 4 and 8 . All families had palate involvement in at least one member of the family although the type of cleft and the extent of palate involvement varied between subjects within the family.

Lod scores resulting from an autosomal dominant model with a gene frequency of 0.001 and penetrances of $80 \%$ and $28 \%$ are presented in tables 2 and 3, respectively. The lod score for families $1,2,4,5,7$, and 8 , including only affected subjects, has also been calculated and is included in table 2. Only family 5 was completely uninformative. With $80 \%$ penetrance a lod score of $Z=-3.152$ at $\theta=0.05$ and $Z=-2.49$ at $\theta=0.05$ was observed. However, by reducing the penetrance to $28 \%$ the lod score increased to $Z=-0.085$ at $\theta=0$ with a maximum lod score of $Z=0.448$ at $\theta=0.2$.

The lod scores resulting from the analysis of the pedigrees by an autosomal recessive model with a gene frequency of 0.035 and a penetrance of $35 \%$ are given in table 4 . Families 2 and 5 were uninformative. A maximum lod of $\mathrm{Z}=0.292$ at $\theta=0.00$ was found but overall the pedigrees were relatively uninformative with this model.

\section{Discussion}

There have been various models proposed for the inheritance of $\mathrm{CL} / \mathrm{P}$. One of these models postulates a major gene locus with autosomal recessive inheritance ${ }^{2}$ while another favours autosomal dominant inheritance. ${ }^{6}$ However, the ability to test these models using genetic markers is made difficult by the infrequency of large, multigeneration families affected with non-syndromic $\mathrm{CL} / \mathrm{P}$.

DNA was available from eight families with a pattern of clefting most consistent with an autosomal dominant mode of inheritance. Four families $(1,2,5$, and 7$)$ had affected

Table 2 Lod scores for two point linkage of CL/P and TGFA, autosomal dominant model, penetrance $=80 \%$.

\begin{tabular}{|c|c|c|c|c|c|c|c|c|}
\hline \multirow[b]{2}{*}{ Pedigree } & \multicolumn{8}{|c|}{ Recombination fraction $(\theta)$} \\
\hline & 0.000 & 0.001 & 0.05 & $0 \cdot 1$ & $0 \cdot 2$ & $0 \cdot 3$ & 0.4 & 0.5 \\
\hline $\begin{array}{l}1 \\
2 \\
3 \\
4 \\
5 \\
6 \\
7 \\
8\end{array}$ & $\begin{array}{r}-3.252 \\
0.903 \\
-0.653 \\
0.268 \\
0.000 \\
-0.397 \\
-3.729 \\
-3.259\end{array}$ & $\begin{array}{r}-2.069 \\
0.901 \\
-0.651 \\
0.268 \\
0.000 \\
-0.388 \\
-2.818 \\
-3.257\end{array}$ & $\begin{array}{r}-0.463 \\
0.815 \\
-0.521 \\
0.267 \\
0.000 \\
-0.132 \\
-1.139 \\
-1.979\end{array}$ & $\begin{array}{r}-0.229 \\
0.725 \\
-0.398 \\
0.251 \\
0.000 \\
-0.014 \\
-0.815 \\
-1.393\end{array}$ & $\begin{array}{r}-0.060 \\
0.542 \\
-0.209 \\
0.189 \\
0.000 \\
0.066 \\
-0.486 \\
-0.795\end{array}$ & $\begin{array}{r}-0.011 \\
0.357 \\
-0.088 \\
0.106 \\
0.000 \\
0.055 \\
-0.292 \\
-0.443\end{array}$ & $\begin{array}{r}-0.001 \\
0.175 \\
-0.021 \\
0.031 \\
0.000 \\
0.018 \\
-0.142 \\
-0.194\end{array}$ & $\begin{array}{l}0.000 \\
0.000 \\
0.000 \\
0.000 \\
0.000 \\
0.000 \\
0.000 \\
0.000\end{array}$ \\
\hline $\begin{array}{l}\text { Total } \\
\text { Total* }\end{array}$ & $\begin{array}{r}-10 \cdot 119 \\
-9.069\end{array}$ & $\begin{array}{l}-8.014 \\
-6.975\end{array}$ & $\begin{array}{l}-3.152 \\
-2.499\end{array}$ & $\begin{array}{l}-1.873 \\
-1.461\end{array}$ & $\begin{array}{l}-0.753 \\
-0.610\end{array}$ & $\begin{array}{l}-0.316 \\
-0.283\end{array}$ & $\begin{array}{l}-0.134 \\
-0.131\end{array}$ & $\begin{array}{l}0.000 \\
0.000\end{array}$ \\
\hline
\end{tabular}

* Total lod score calculated on families with dominant pattern of inheritance (families 1, 2, 4, 5, 7, and 8) using affected subjects only.

Table 3 Lod scores for two point linkage of $C L / P$ and $T G F A$, autosomal dominant model, penetrance $=28 \%$.

\begin{tabular}{|c|c|c|c|c|c|c|c|c|}
\hline \multirow[b]{2}{*}{ Pedigree } & \multicolumn{8}{|c|}{ Recombination fraction $(\theta)$} \\
\hline & 0.000 & 0.001 & 0.05 & $0 \cdot 1$ & $0 \cdot 2$ & 0.3 & $0 \cdot 4$ & 0.5 \\
\hline $\begin{array}{l}1 \\
2 \\
3 \\
4 \\
4 \\
5 \\
6 \\
7 \\
8\end{array}$ & $\begin{array}{r}-0.477 \\
0.705 \\
0.772 \\
-0.366 \\
0.000 \\
-0.373 \\
-0.180 \\
-0.166\end{array}$ & $\begin{array}{r}-0.471 \\
0.704 \\
0.771 \\
-0.366 \\
0.000 \\
-0.368 \\
-0.178 \\
-0.166\end{array}$ & $\begin{array}{r}-0.282 \\
0.624 \\
0.690 \\
-0.324 \\
0.000 \\
-0.206 \\
-0.094 \\
-0.174\end{array}$ & $\begin{array}{r}-0.174 \\
0.543 \\
0.604 \\
-0.261 \\
0.000 \\
-0.102 \\
-0.045 \\
-0.175\end{array}$ & $\begin{array}{r}-0.066 \\
0.384 \\
0.422 \\
-0.141 \\
0.000 \\
0.010 \\
-0.003 \\
-0.158\end{array}$ & $\begin{array}{r}-0.021 \\
0.235 \\
0.234 \\
-0.059 \\
0.000 \\
0.047 \\
0.005 \\
-0.119\end{array}$ & $\begin{array}{r}-0.004 \\
0.106 \\
0.070 \\
-0.014 \\
0.000 \\
0.038 \\
0.002 \\
-0.065\end{array}$ & $\begin{array}{l}0.000 \\
0.000 \\
0.000 \\
0.000 \\
0.000 \\
0.000 \\
0.000 \\
0.000\end{array}$ \\
\hline Total & -0.085 & -0.074 & 0.234 & 0.39 & 0.448 & 0.322 & 0.133 & 0.000 \\
\hline
\end{tabular}


Table 4 Lod scores for two point linkage of $C L / P$ and TGFA, autosomal recessive model, penetrance $=35 \%$.

\begin{tabular}{lrrrrrrrr}
\hline & \multicolumn{7}{c}{ Recombination fraction $(\theta)$} \\
\cline { 2 - 9 } Pedigree & \multicolumn{1}{c}{0.000} & \multicolumn{1}{c}{0.001} & \multicolumn{1}{c}{0.05} & \multicolumn{1}{c}{0.1} & \multicolumn{1}{c}{0.2} & \multicolumn{1}{c}{0.3} & \multicolumn{1}{c}{0.4} & 0.5 \\
\hline 1 & -0.212 & -0.211 & -0.167 & -0.129 & -0.07 & -0.031 & -0.008 & 0.000 \\
2 & 0.000 & 0.000 & 0.000 & 0.000 & 0.000 & 0.000 & 0.000 & 0.000 \\
3 & 0.321 & 0.320 & 0.263 & 0.209 & 0.119 & 0.053 & 0.013 & 0.000 \\
4 & 0.050 & 0.049 & 0.037 & 0.027 & 0.013 & 0.005 & 0.001 & 0.000 \\
5 & 0.000 & 0.000 & 0.000 & 0.000 & 0.000 & 0.000 & 0.000 & 0.000 \\
6 & -0.036 & -0.036 & -0.029 & -0.022 & -0.012 & -0.005 & -0.001 & 0.000 \\
7 & 0.085 & 0.085 & 0.070 & 0.056 & 0.033 & 0.015 & 0.004 & 0.000 \\
8 & 0.084 & 0.084 & 0.069 & 0.055 & 0.032 & 0.014 & 0.003 & 0.000 \\
Total & 0.292 & 0.291 & 0.243 & 0.196 & 0.115 & 0.051 & 0.012 & 0.000 \\
\hline
\end{tabular}

subjects in three generations. Family 4 also had affected subjects in three generations with non-penetrance in II.6, and family 8 had affected subjects in two generations with nonpenetrance in II.2. Families 3 and 6 were less convincingly dominant and could be interpreted as showing recessive inheritance. This type of pedigree could result from a gene carrier entering the family through marriage (II.5 in pedigree 3 and II.6 in pedigree 6).

For the linkage analysis based on an autosomal dominant model, the penetrance was set at $80 \%$ as this best reflected the level of nonpenetrance observed in our families. Crossovers in five out of seven informative families were found and the final lod score of $Z=-3.152$ at $\theta=0.00$ indicates that TGFA is not closely linked to the clefting phenotype in these families.

In family 1 the haplotype C2A2B1 has been passed on by the affected father II.2 to both his affected daughters, III.1 and III.2. It is not possible to define unequivocally the full haplotype in the father's affected brother II.3 who had a 'forme fruste' of $\mathrm{CL} / \mathrm{P}$, but looking only at the TaqI polymorphism it can be seen that they do not share a common allele.

Family 2 is fully informative for analysis of the haplotype and contains only affected subjects. No crossovers were observed but the family is only sufficiently large to generate a maximum lod score of 0.903 at $\theta=0.00$.

Family 7 is also fully informative for TGFA segregation. The affected grandfather, I.2, passed the haplotype C1A2B2 onto both affected children, II.2 and II.3. His affected son II. 2 passed the other chromosome containing haplotype $\mathrm{C} 1 \mathrm{~A} 1 \mathrm{~B} 1$ on to his affected daughter III.2, representing a crossover in an affected subject, and additionally passed the high risk haplotype $\mathrm{C} 1 \mathrm{~A} 2 \mathrm{~B} 2$ on to his unaffected daughter, III.1.

In family 8, the two affected grandchildren, III. 1 and III.3, have both inherited the haplotype C1A2B2 from their mother, II.2, which she had inherited from her unaffected mother rather than her affected father. The affected persons in generations I and III therefore do not share a common gene.

In family 3, all four children in generation II inherited the same chromosome from both parents although only two are affected, whereas in family 6 affected subject II .5 passed the same allele on to her affected and unaffected child.

The pedigrees were also analysed using the same gene frequency and reduced penetrance as described by Hecht et al. ${ }^{10}$ The final maximum lod score of $Z=0.448$ at $\theta=0.2$ lends no support for TGFA as the major gene in these families. The lod score in family 3 was considerably higher with the reduced penetrance. This presumably is owing to unaffected subjects II.1 and II.2, who have the same haplotype as their affected sibs II.3 and II.4, having a greater chance of being non-penetrant. Hecht et $a l^{10}$ also reported no linkage between TGFA and CL/P in 12 families tested with this model.

Our final model for linkage analysis was based on an autosomal recessive model first described by Chung et al. ${ }^{2}$ However, as our families were chosen for their apparently dominant mode of inheritance, they provide relatively little information with this model. Affected parents would be scored as homozygous and therefore uninformative for the $\mathrm{CL} / \mathrm{P}$ locus. A lod score of $Z=0.292$ at $\theta=0.00$ was generated with a penetrance of $35 \%$ and a gene frequency of 0.035 . A crossover was evident in family 1 as subject II.1 passed on different alleles to two affected children. In family 3 , the positive lod score is again thought to arise from the reduced penetrance and inheritance of the same haplotypes in generation II.

The results from the three linkage analyses performed on our families all indicate a lack of linkage between TGFA and the CL/P phenotype. Although the autosomal recessive model generated a slightly positive lod score at $\theta=0.00$, and the autosomal dominant model with reduced penetrance a weakly positive lod score at $\theta=0 \cdot 2$, these results are not indicative of TGFA being the gene of major effect causing $C L / P$ in these families. It is possible that $\mathrm{CL} / \mathbf{P}$ is genetically heterogeneous making it difficult to prove linkage by pooling families. Two families had positive lod scores; family 2 with $\mathrm{Z}=0.903$ at $\theta=0.00$ in the autosomal dominant model with $80 \%$ penetrance, and family 3 with $Z=0.772$ at $\theta=0.00$ in the autosomal dominant model with $28 \%$. However, in the other five informative families there was definite recombination.

TGFA was selected as a candidate gene for cleft lip and palate because of its role in normal and abnormal palatogenesis in rodents. The finding of an association between a TGFA polymorphism and cleft lip provides evidence for the role of TGFA in the development of the facial processes in humans. ${ }^{11}$ However, in the majority of apparently autosomal dominant pedigrees studied here, there is no evidence that TGFA is the gene of major effect causing 
$\mathrm{CL} / \mathrm{P}$. It is possible that the families are either segregating for another major gene or that CL/ $P$ is genetically heterogeneous with specific alleles at the TGFA locus only contributing to a proportion of cases. Alternatively, as it was predicted by Chung $e t a l^{2}$ that only one-third of $\mathrm{CL} / \mathrm{P}$ cases would be accounted for by a major gene, our families may not be suitable for this type of analysis. A better approach to resolve the involvement of TGFA and familial $\mathrm{CL} / \mathrm{P}$ may be to carry out a sib-pair analysis, which has the advantage of not requiring a model, and which may indicate if TGFA is a major gene involved in clefting.

In conclusion, although several studies have reported a significant association between TGFA and unrelated clefted subjects, ${ }^{3-5}$ we have found no evidence of linkage between TGFA and families with an apparently autosomal dominant inheritance of $\mathrm{CL} / \mathrm{P}$.

This work was generously supported by the Child Health Research Appeal Trust. Dr S Holder is supported by a Medical Research Council Grant. We thank Dr Jeff Murray for helpful discussions.
1 Holder SE. Cleft lip - is there light at the end of the tunnel? Arch Dis Child 1991;66:829-30.

2 Chung CS, Bixler D, Watanabe T, Koguchi $H$, Fogh-Anderson P. Segregation analysis of cleft lip with or without cleft palate: a comparison of Danish and Japanese data. Am f Hum Genet 1986;39:603-11.

3 Ardinger $\mathrm{HH}$, Buetow $\mathrm{KH}$, Bell GI, Bardach J, VanDemark DR, Murray JC. Association of genetic variation of the transforming growth factor-alpha gene with cleft lip and palate. Am $\mathcal{f}$ Hum Genet 1989;45:348-53.

4 Holder SE, Vintiner GM, Farren B, Malcolm S, Winter RM. Confirmation of an association between RFLPs at the transforming growth factor-alpha locus and nonsyndromic cleft lip and palate. $\mathcal{f}$ Med Genet 1992;29: 390-2.

5 Chenevix-Trench G, Jones K, Green A, Martin N. Further evidence for an association between genetic variation in transforming growth factor alpha and cleft lip and palate. Am f Hum Genet 1991;48:1012-3.

6 Hecht JT, Yang P, Michels VV, Buetow KH. Complex segregation analysis of nonsyndromic cleft lip and palate. Am $\mathcal{F}$ Hum Genet 1991;49:674-81.

7 Temple K, Calvert M, Plint D, Thompson E, Pembrey M. Dominantly inherited cleft lip and palate in two families. f Med Genet 1989;26:386-9.

8 Murray JC, Buetow KH, Bell GI. RFLPs for transforming growth factor alpha (TGFA) gene at 2p13. Nucleic Acids Res 1986;14:5117.

9 Hayward NK, Nancarrow DJ, Bell GI. A TaqI polymorphism for the human transforming growth factor alpha gene (TGFA). Nucleic Acids Res 1987;15:5503.

10 Hecht JT, Wang Y, Blanton SH, Michels VV, Daiger SP. Cleft lip and palate: no evidence of linkage to transforming growth factor alpha. Am ₹ Hum Genet 1991;49:682-6.

11 Ferguson MWJ. Palate development: mechanisms and malformations. Ir f Med Sci 1983;156:309-15. 